\title{
«Diderot Studies», tome XXX, edited by Thierry Belleguic
}

Paola Sosso

\section{(2) OpenEdition}

1 Journals

\section{Edizione digitale}

URL: http://journals.openedition.org/studifrancesi/7946

DOI: $10.4000 /$ studifrancesi.7946

ISSN: 2421-5856

\section{Editore}

Rosenberg \& Sellier

\section{Edizione cartacea}

Data di pubblicazione: 1 juillet 2009

Paginazione: 404-405

ISSN: 0039-2944

\section{Notizia bibliografica digitale}

Paola Sosso, ««Diderot Studies», tome XXX, edited by Thierry Belleguic», Studi Francesi [Online], 158 (LIII | II) | 2009, online dal 30 novembre 2015, consultato il 10 janvier 2021. URL: http:// journals.openedition.org/studifrancesi/7946 ; DOI: https://doi.org/10.4000/studifrancesi.7946

Questo documento è stato generato automaticamente il 10 janvier 2021.

\section{(c) (i) (9)}

Studi Francesi è distribuita con Licenza Creative Commons Attribuzione - Non commerciale - Non opere derivate 4.0 Internazionale. 


\title{
«Diderot Studies», tome XXX, edited by Thierry Belleguic
}

\author{
Paola Sosso
}

\section{NOTIZIA}

«Diderot Studies», tome XXX, edited by Thierry BELLEGUIC, Paris, 2008, pp. 349.

1 La maggior parte («The First Salons») è dedicata ai Salons che Diderot iniziò a comporre nel 1759 quando le esposizioni alla Cour du Palais Royal erano un'istituzione ormai riconosciuta e apprezzata. Come ricorda la Présentation del curatore, Diderot si trasforma in breve tempo da philosophe amateur in connaisseur averti di uno specifico linguaggio tecnico. Il primo articolo si occupa della genesi dei primi Salons. Shane AGIN, The Development of Diderot's Salons and the Shifting Boundary of Representational Language, pp. 11-30) mettendoli in rapporto con le opere precedenti del filosofo. Nel secondo intervento (Les "Essais sur la peinture" ou la place de la théorie, pp. 31-52) Michel DeloN ricostruisce il lavoro teorico del critico d'arte di fronte all'opera; sulla scorta di numerosi esempi, l'autore ci mostra il ruolo di alcuni concetti chiave come la déformation, il rapporto tra esseri ideali e reali, la contemplazione dell'opera come esplorazione che trasforma, la variazione del punto di vista come possibilità dinamica di comprensione del quadro in un'incessante interazione tra esperienza e riflessione. Stéphane LoJKINE (Le problème de la description dans les "Salons" de Diderot, pp. 53-72) focalizza la sua attenzione su vari aspetti della descrizione diderotiana considerata sotto vari punti di vista: come forma di meditazione, come deludente tensione verso l'impossibile e nella sua funzione di dispositivo tecnico. In Note sur la communication des passions en peinture: le "Salon de 1763" (pp. 73-88) Mitia RiouX-BEAULNE mostra come la teoria di Diderot sull'identificazione sia nata nel contesto della nuova concezione del teatro e sia poi stata ripresa come tecnica per la critica d'arte in particolare nel Salon del 1763. Florence BOULERIE (Diderot et le vocabulaire technique de l'art: des premiers "Salons" aux "Essais sur la peinture", pp. 89-112) si interroga sull'influenza avuta dal 
linguaggio usato da pittori e scultori sull'invenzione della critica d'arte di Diderot, mentre i due saggi successivi si soffermano su alcuni aspetti legati al colore (Marian HoBson, Le temps de la couleur: le "Salon de 1763" de Diderot, pp. 113-124, Katalin KovACS, La couleur et le sentiment de la chair dans les premiers "Salons" de Diderot, pp. 125-143). Stéphanie GENAND (L'œil ravi: violences du regard dans les premiers "Salons" de Diderot, pp. 143-154) ci spiega come per Diderot la capacità di suscitare emozione attraverso una forza vigorosa è ciò che distingue il vero pittore dai falsi artisti. La rappresentazione del nudo è uno dei principali vettori dell'emozione del critico Diderot: questo elemento è analizzato nei suoi aspetti contraddittori da Jean-Christophe ABRAMOVICI in Voir le nu dans les premiers "Salons" (pp. 165-178). Del rapporto di Diderot con le opere sacre, del suo tono a volte polemico, a volte entusiasta, spesso ammirato, si interessa lo studio di Paul PelcKmans La violence du sacré dans les premiers "Salons" (pp. 165-178). Nel progetto dei Salons, sottolinea poi Geneviève CAMMAGRE (Enjeux rhétoriques et esthétiques de la représentation de soi, pp. 179-194), entra in gioco anche una rappresentazione del critico che emette verdetti sulle opere d'arte: interessante è allora rilevare il rapporto tra soggettività e oggettività, tra retorica ed estetica. Degno di rilievo anche il suggerimento di Kate E. TUNSTALl (Paradoxe sur le portrait: autoportrait de Diderot en Montaigne, pp. 195-209), che nota come nel Salon de 1767, in cui Diderot commenta il suo ritratto composto da Van Loo, vi sia un chiaro riferimento agli Essais di Montaigne. Ancora di intertestualità si occupa Bernadette FORT in Intertextuality and Iconoclasm: Diderot's "Salon of 1775" (pp. 209-245).

2 Il volume si conclude con una sezione di «Miscellaneous articles»: i primi tre articoli (Anthony WALL, Curiosity printed on several Faces, including Diderot's, pp. 249-274; Phoebe Von Held, Mad Mimetics: Alienation and Theatricality in the Figure of the Neveu de Rameau, pp. 275-294; Jean-Pierre CLERO, Le savoir des fictions chez Diderot: la prosopopée de la fiction, pp. 295-326) sono seguiti dall'intervento di Raymond Trousson (Diderot au théâtre, pp. 327-349), che ci ricorda come spesso l'homme de lettres del Secolo dei Lumi sia diventato protagonista di opere teatrali, basti pensare a Les philosophes di Palissot del 1760. Certo furono soprattutto Voltaire e Rousseau a varcare le scene, perché Diderot era meno noto al pubblico e la sua attività legata per lo più all'Encyclopédie. Trousson ripercorre $\mathrm{i}$ vari testi che, dopo quello di Palissot, hanno presentato la figura di Diderot attraversando i secoli per arrivare, tra vaudevilles e commedie borghesi, fino ai nostri giorni (l'ultima rappresentazione teatrale ricordata risale al 2005). 